\title{
Auro: Avaliação do nível de atividade física durante a gestação
}

FRANCISCO TRINDADE SIIVA

ORIENTADOR:

Prof. Dr. Fabrício da Silva COSTA

\author{
Physical activity level evaluation during pregnancy
}

Resumo de tese

Palavras-chave

Gravidez normal Atividade Física Gasto energético

Key words

Normal pregnancy

Physical activity

Energy expenditure

LÚCIA DO RÊGO RODRIGUES COSTA

ORIENTADOR:

Prof. Dr. Fabrício da Silva Costa

Resumo de tese

Palavras-chave

Gestação de alto-risco Fatores de riscos maternos Unidade de terapia intensiva neonatal

Assistência pré-natal

Key words

High risk pregnancy

Maternal risk factors

Neonatal intensive care unit Prenatal care
Dissertação apresentada ao Curso de Mestrado Profissional em Saúde Pública da Universidade Estadual do Ceará (UECE), Área de concentração Saúde Pública, em 16 de abril de 2007

OBJETIVO: mensurar o gasto energético em gestantes através de um questionário, o Pregnancy Physical Activity Questionnaire - PPAQ, proposto por Chasan-Taber (2004). MÉTODOS: estudo de natureza quantitativa descritiva, de corte transversal. Realizou-se em 12 unidades municipais de saúde de Fortaleza, pertencentes à Secretária Executiva Regional IV. A amostra do estudo corresponde a 305 gestantes atendidas nos postos de saúde da regional. O PPAQ, para adequar-se à realidade brasileira, foi validado durante fases do estudo e direcionado por metodologia da Organização Mundial de Saúde (OMS). O questionário capta o gasto energético em Metabolic Equivalents Tasks (METs); sendo classificado quanto à intensidade em "sedentário" (<1,5 METs), "leve" (1,5 a <3,0 METs), "moderado" (3,0 a 6,0 METs) e "vigoroso" (>6,0 METs). Para processar as informações utilizou-se o Epi-info 6.04a. A associação entre variáveis foi testada pelo $X^{2}$ ou pelo Teste Exato de Fisher, com 5\% de significância. RESULTADOS: Foram incluídas 305 gestantes, sendo a prevalência de gasto energético classificado como "leve" foi encontrado em 51,4\% dos casos e, quando agrupamos atividade "sedentário" e "leve", este valor cresce para $80,3 \%$, mostrando que há uma prevalência de inatividade física durante o período gestacional. Com o desenvolvimento da gestação, percebe-se um discreto aumento na classificação da atividade "leve" para os três trimestres, 44,9, 57,3 e 61,4\% e uma acentuada redução na classificação "moderado", 29,1, 25,2 e 4,5\%. Apresentaram nível de significância as variáveis: trimestre de gestação, escolaridade, estado civil e raça com relação ao gasto energético. CONCLUSÃO: ○ QAFG mostrou-se importante instrumento na captação de gasto energético para gestantes e pode ser utilizado para obter informação sobre o nível de atividade física de gestantes em comunidades e para incrementar programas em políticas de saúde pública.

\section{Fatores de risco maternos associados à necessidade de UTI neonatal}

\author{
Risk factors associated to the need for neonatal intensive care unit'
}

Dissertação apresentada ao Curso de Mestrado Profissional em Saúde da Criança e do Adolescente da Universidade Estadual do Ceará (UECE), na Área de Conhecimento Saúde da Criança e do Adolescente, em 9 de março de 2007.

OBJETIVO: conhecer os fatores de risco maternos que levam os recém-nascidos a necessitarem de internação em Unidade de Terapia Intensiva Neonatal (UTI Neo), em um hospital público do Sistema Único de Saúde (SUS) de nível terciário do município de Fotaleza-CE. MÉTODO: estudo caso-controle, com amostra de 222 mães. O grupo de casos foi formado de todas as mães dos recém-nascidos que necessitaram de internação em UTI Neo, Em um pareamento 1 caso: 1 controle, em um período de seis meses (julho-dezembro 2006). Os dados foram analisados no Software Stata v.7. As proporções foram comparadas através do teste Exato de Fisher ou do teste do qui-quadrado de Pearson. No modelo multivariado foi utilizado Odds Ratio (OR) ajustado com intervalo de confiança de 95\%. RESULTADOS: há vários fatores de risco envolvidos que se interrelacionam, apresentando significância estatística, para a necessidade de internação em UTI Neo: internação durante a gravidez $(p=0,007)$, doença durante a gravidez $(p=0,000)$, hipertensão arterial $(p=0,002)$, nível 1 de Coutinho inadequado $(p=0,040)$, nível 2 de Coutinho inadequado $(p=0,031)$, nível 3 de Coutinho inadequado $(p=0,029)$, tipo de gestação gemelar $(p=0,010)$, ruptura precoce de membranas ( $p=0,000)$. CONCLUSÃO: as síndrome hipertensivas na gestação e ruptura precoce de membranas devem ter atenção especial na gestação configurando-a como de alto risco. $\bigcirc$ processo de assistência pré-natal prestada às usuárias do SUS, a despeito da alta cobertura, apresentou baixa adequação em todos os níveis estudados e relação com a internOação em UTI Neo. 